\title{
Lithium-Ion Mobility in Quaternary Boro-Germano-Phosphate Glasses
}

\author{
Andrea Moguš-Milanković, ${ }^{* \dagger}{ }^{\dagger}$ Kristina Sklepić, ${ }^{\dagger}$ Petr Mošner, ${ }^{\ddagger}$ Ladislav Koudelka, ${ }^{\ddagger}$ and Petr Kalenda \\ ${ }^{\dagger}$ Ruđer Bošković Institute, Division of Materials Chemistry, 10000 Zagreb, Croatia \\ ${ }^{\ddagger}$ Department of General and Inorganic Chemistry, University of Pardubice, Faculty of Chemical Technology, 53210 Pardubice, Czech \\ Republic
}

\begin{abstract}
Effect of the structural changes, electrical conductivity, and dielectric properties on the addition of a third glass-former, $\mathrm{GeO}_{2}$, to the borophosphate glasses, $40 \mathrm{Li}_{2} \mathrm{O}-10 \mathrm{~B}_{2} \mathrm{O}_{3}-(50-x) \mathrm{P}_{2} \mathrm{O}_{5}-x \mathrm{GeO}_{2}, x=0-25$ mol \%, has been studied. Introduction of $\mathrm{GeO}_{2}$ causes the structural modifications in the glass network, which results in a continuous increase in electrical conductivity. Glasses with low $\mathrm{GeO}_{2}$ content, up to $10 \mathrm{~mol} \%$, show a rapid increase in dc conductivity as a result of the interlinkage of slightly depolymerized phosphate chains and negatively charged $\left[\mathrm{GeO}_{4}\right]^{-}$units, which enhances the migration of $\mathrm{Li}^{+}$ions. The $\mathrm{Li}^{+}$ions compensate these delocalized charges connecting both phosphate and germanium units, which results in reduction of both bond effectiveness and binding energy of $\mathrm{Li}^{+}$ions and therefore enables their hop to the next charge-compensating site. For higher $\mathrm{GeO}_{2}$ content, the dc conductivity increases slightly, tending to approach a

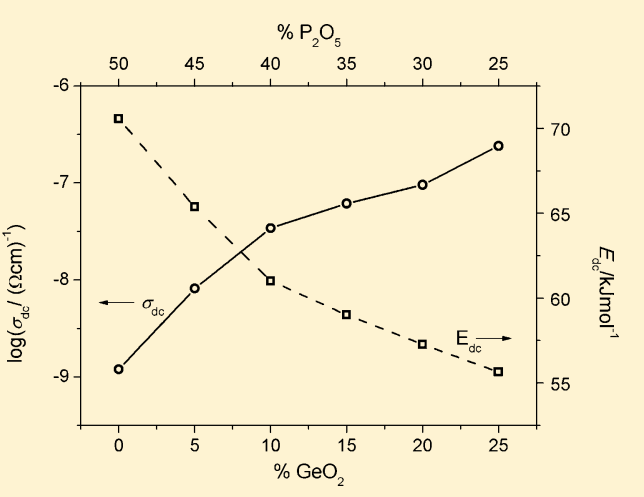
maximum in $\mathrm{Li}^{+}$ion mobility caused by the incorporation of $\mathrm{GeO}_{2}$ units into phosphate network combined with conversion of $\mathrm{GeO}_{4}$ to $\mathrm{GeO}_{6}$ units. The strong cross-linkage of germanium and phosphate units creates heteroatomic $\mathrm{P}-\mathrm{O}-\mathrm{Ge}$ bonds responsible for more effectively trapped $\mathrm{Li}^{+}$ions. A close correspondence between dielectric and conductivity parameters at high frequencies indicates that the increase in conductivity indeed is controlled by the modification of structure as a function of $\mathrm{GeO}_{2}$ addition.
\end{abstract}

\section{INTRODUCTION}

Over recent years, many novel glasses and ceramic materials are being investigated for their potential applications as solid electrolytes in batteries. ${ }^{1,2}$ Special attention is given to improve the stability, safety, and required performance of lithium-ion batteries such as high energy density, long cycle life, and wide operating temperature range. Usually, lithium electrolytes consist of lithium salts and organic polymer liquids. In contrast, the inorganic solid electrolytes such as glass-based lithium electrolytes show both advantages and disadvantages over the organic liquid solvents. An ideal electrolyte material should be able to replete and transfer $\mathrm{Li}^{+}$ions from the anode to the cathode without deterioration. Generally, inorganic solid electrolytes are single-ion conductors that eliminate the anionic concentration gradient across the electrolyte, prevent the decomposition of electrolyte, expand the choice of electrode materials, and allow operation at higher voltages. ${ }^{1,3}$

Several approaches have been suggested and investigated in order to enhance the ionic conductivity of glassy-based electrolytes. One of them is called the mixed glass network former effect (MGFE), where the ionic conductivity enhancement is observed when one network former is progressively substituted by another while keeping the total ion concentration constant. ${ }^{4}$

MGFE has been investigated in various ternary alkali borophosphate, germanophosphate, and borogermanate glass systems. ${ }^{5-8}$ The increase in the ionic conductivity at room temperature was first observed by Magistris et al. ${ }^{9}$ as a result of the replacement of $\mathrm{B}_{2} \mathrm{O}_{3}$ by $\mathrm{P}_{2} \mathrm{O}_{5}$ at constant lithium content. Similar results of the conductivity enhancement in lithium borophosphate systems were observed in several recent studies. ${ }^{10-12}$ These studies indicate that the conductivity increase is a result of structural changes in the glass network. The increase of $\mathrm{P}-\mathrm{O}-\mathrm{B}$ and $\mathrm{B}-\mathrm{O}-\mathrm{B}$ bonds accompanied by the decrease of $\mathrm{P}-\mathrm{O}-\mathrm{P}$ bonds and nonbridging oxygens is observed with increasing $\mathrm{B}_{2} \mathrm{O}_{3}$ content. Phosphate chains are cross-linked through $\mathrm{B}-\mathrm{O}-\mathrm{P}$ bonds, and it was suggested that the $\mathrm{P}-\mathrm{O}-\mathrm{B}$ bonds containing $\mathrm{BO}_{4}$ units have a stronger structure-modifying and conductivity-enhancing effect than bonds containing $\mathrm{BO}_{3}$ units. ${ }^{11,12}$

Recently, the structural changes caused by mixed former effect in alkali ion-conducting germanophosphate systems were characterized using a combination of various spectroscopies such as X-ray photoelectron spectroscopy (XPS) and ${ }^{31} \mathrm{P}$ nuclear magnetic resonance (MAS NMR) techniques. ${ }^{13,14}$ In these detailed spectroscopic analyses, it was found that the formation of heteroatomic $\mathrm{P}-\mathrm{O}-\mathrm{Ge}$ linkages are moderately favored over homoatomic $\mathrm{P}-\mathrm{O}-\mathrm{P}$ and $\mathrm{Ge}-\mathrm{O}-\mathrm{Ge}$ bonds. In 
Table 1. Composition, Glass Transition Temperature, $T_{\mathrm{g}}$, Dilatometric Softening Temperature, $T_{\mathrm{d}}$, Thermal Expansion Coefficient, $\alpha$, and Selected Electrical Properties for the $40 \mathrm{Li}_{2} \mathrm{O}-10 \mathrm{~B}_{2} \mathrm{O}_{3}-(50-x) \mathrm{P}_{2} \mathrm{O}_{5}-x \mathrm{GeO}_{2}, x=0-25$ mol \%, Glasses

\begin{tabular}{|c|c|c|c|c|c|c|c|c|c|}
\hline \multirow[b]{2}{*}{ sample } & \multicolumn{4}{|c|}{ glass composition ( $\mathrm{mol} \%)$} & \multirow[b]{2}{*}{$T_{\mathrm{g}} \pm 2\left({ }^{\circ} \mathrm{C}\right)$} & \multirow[b]{2}{*}{$T_{\mathrm{d}} \pm 2\left({ }^{\circ} \mathrm{C}\right)$} & \multirow[b]{2}{*}{$\alpha \pm 3\left(\mathrm{ppm}{ }^{\circ} \mathrm{C}^{-1}\right)$} & \multirow[b]{2}{*}{$\sigma_{\mathrm{dc}}\left((\Omega \mathrm{cm})^{-1}\right)( \pm 0.5 \%)^{a}$} & \multirow[b]{2}{*}{$E_{\mathrm{dc}}\left(\mathrm{kJ} \mathrm{mol}^{-1}\right)( \pm 0.5 \%)$} \\
\hline & $\mathrm{Li}_{2} \mathrm{O}$ & $\mathrm{B}_{2} \mathrm{O}_{3}$ & $\mathrm{P}_{2} \mathrm{O}_{5}$ & $\mathrm{GeO}_{2}$ & & & & & \\
\hline Ge- 0 & 40 & 10 & 50 & 0 & 367 & 384 & 16.9 & $1.20 \times 10^{-9}$ & 70.57 \\
\hline Ge-5 & 40 & 10 & 45 & 5 & 397 & 419 & 16.3 & $8.18 \times 10^{-9}$ & 65.37 \\
\hline Ge-10 & 40 & 10 & 40 & 10 & 433 & 456 & 14.9 & $3.42 \times 10^{-8}$ & 61.02 \\
\hline Ge-15 & 40 & 10 & 35 & 15 & 445 & 463 & 14.7 & $6.14 \times 10^{-8}$ & 59.01 \\
\hline Ge-20 & 40 & 10 & 30 & 20 & 449 & 468 & 14.5 & $9.56 \times 10^{-8}$ & 57.27 \\
\hline Ge-25 & 40 & 10 & 25 & 25 & & & & $2.41 \times 10^{-7}$ & 55.65 \\
\hline
\end{tabular}

contrast, in these sodium germanophosphate glass compositions, the phosphate component is predominantly modified by sodium ions because sodium ions are associated with nonbridging oxygens on phosphate tetrahedral. Consequently, the sodium ions majorly modified the phosphate rather than the germanate component in the network. ${ }^{14}$

In the context of the lithium battery application and ionic conductivity enhancement, it is of interest to investigate how the reorganization of glass network affects the mobility of lithium ions in quaternary mixed matrix $\mathrm{Li}_{2} \mathrm{O}-\mathrm{B}_{2} \mathrm{O}_{3}-\mathrm{P}_{2} \mathrm{O}_{5}-$ $\mathrm{GeO}_{2}$ glass system. In our previous studies, we reported that the addition of germanium oxide as a third glass former to the lithium borophosphate glasses causes an increase in ionic conductivity through the formation of ion-conducting channels arising from structural modification and formation of $\mathrm{P}-\mathrm{O}-\mathrm{Ge}$ bonds that favors an easy migration of lithium ions along these bonds. ${ }^{15,16}$ However, in the studied glasses the lithium concentration as well as other contents was changed simultaneously with $\mathrm{GeO}_{2}$ addition.

In the present work, our interest is to report the effect of the addition of germanium oxide on the electrical conductivity and dielectric properties of the ternary $\mathrm{Li}_{2} \mathrm{O}-\mathrm{B}_{2} \mathrm{O}_{3}-\mathrm{P}_{2} \mathrm{O}_{5}$ glass system, whereas the lithium ion concentration and $\mathrm{B}_{2} \mathrm{O}_{3}$ content are kept constant. Therefore, it would be interesting to investigate how the tendency of depolymerization of phosphate chains along with the incorporation of germanate units into phosphate network affects the lithium ion transport of these glasses. Furthermore, the changes in its electrical properties, frequency, and temperature dependence have been discussed on the basis of the competitions between breaking/ forming structural groups and lithium ion transport.

\section{EXPERIMENTAL SECTION}

Glasses in the $40 \mathrm{Li}_{2} \mathrm{O}-10 \mathrm{~B}_{2} \mathrm{O}_{3}-(50-x) \mathrm{P}_{2} \mathrm{O}_{5}-x \mathrm{GeO}_{2}, x=0-$ $25 \mathrm{~mol} \%$, system were prepared from analytical-grade $\mathrm{Li}_{2} \mathrm{CO}_{3}$, $\mathrm{H}_{3} \mathrm{PO}_{4}, \mathrm{H}_{3} \mathrm{BO}_{3}$, and $\mathrm{GeO}_{2}$ in batches of $10 \mathrm{~g}$ using Pt crucible. First, the homogenized starting mixtures were slowly heated up to $600{ }^{\circ} \mathrm{C}$ for $2 \mathrm{~h}$ to remove water, and then the reaction mixture was melted at $1100-1200{ }^{\circ} \mathrm{C}$ in a covered Pt crucible. After $30 \mathrm{~min}$ of heating at this temperature, the obtained melt was poured into preheated graphite molds to form suitable glass blocks. Obtained glasses were annealed for $30 \mathrm{~min}$ at a temperature below their glass transition temperature and then slowly cooled to room temperature to improve their mechanical properties. The vitreous state was checked by $\mathrm{XRD}$. The composition of glasses studied in this paper is listed in Table 1.

Dilatometric measurements were done on bulk samples of the dimensions $5 \times 5 \times 20 \mathrm{~mm}$ with the horizontal pushrod dilatometer DIL 402PC (NETZSCH) at the heating rate of 5 ${ }^{\circ} \mathrm{C} \mathrm{min}^{-1}$. From TD curves, glass transition temperature $T_{\mathrm{g}}$, dilatation softening temperature, $T_{\mathrm{d}}$, and the coefficient of thermal expansion, $\alpha$, in the temperature range of $150-250{ }^{\circ} \mathrm{C}$ were determined.

The Raman spectra in the range $1400-200 \mathrm{~cm}^{-1}$ were measured on bulk samples at room temperature using a HoribaJobin Yvon LaBRam HR spectrometer. The spectra were recorded in backscattering geometry under excitation with $\mathrm{Nd}$ :YAG laser radiation $(532 \mathrm{~nm})$ at a power of $15 \mathrm{~mW}$ on the sample. The spectral slit width was $1.5 \mathrm{~cm}^{-1}$, and the total integration time was $50 \mathrm{~s}$.

${ }^{31} \mathrm{P}$ MAS NMR spectra were measured at $9.4 \mathrm{~T}$ on a 400 $\mathrm{MHz}$ BRUKER Avance spectrometer with a $4 \mathrm{~mm}$ probe. The spinning speed was $12.5 \mathrm{kHz}$ and relaxation (recycling) delay was $180 \mathrm{~s}$. The chemical shifts of ${ }^{31} \mathrm{P}$ nuclei are given relative to $85 \% \mathrm{H}_{3} \mathrm{PO}_{4}$ at $0 \mathrm{ppm} .{ }^{11} \mathrm{~B}$ MAS NMR spectra were obtained using Bruker Avance 800 spectrometer with a $2.5 \mathrm{~mm}$ probe at $18.8 \mathrm{~T}$. The spinning speed was $20 \mathrm{kHz}$. A rotor-synchronized echo was used with selective pulse lengths of $5 \mu \mathrm{s}$, with an echo delay of $50 \mu \mathrm{s}$ and a $10 \mathrm{~s}$ recycling delay. The chemical shifts of ${ }^{11} \mathrm{~B}$ nuclei are given relative to $\mathrm{BPO}_{4}$ at $-3.6 \mathrm{ppm}$. The NMR spectra deconvolution was done using the Dmfit NMR software. $\mathrm{BO}_{4}$ lines are known to be subjected to negligible second-order quadrupolar effect, so the decomposition was performed using Gaussian-type function assuming that the line shape is dominated by chemical shift distribution.

Samples for electrical properties measurements were cut into $\sim 1 \mathrm{~mm}$ thick disks and polished. Gold electrodes, $7 \mathrm{~mm}$ in diameter, were sputtered onto both sides of the sample using Sputter Coater SC7620. Samples were stored in a desiccator until measurements were performed.

Electrical and dielectric properties were obtained by measuring complex impedance using an impedance analyzer (Novocontrol Alpha-AN Dielectric Spectrometer, Novocontrol Technologies GmbH \& Co. KG, Germany) in a wide frequency range $(0.01 \mathrm{~Hz}$ to $1 \mathrm{MHz})$ and at the temperature range from 183 to $523 \mathrm{~K}$. The temperature was controlled to an accuracy of $\pm 0.2 \mathrm{~K}$.

Equivalent circuits modeling was used to analyze the impedance spectra, and the corresponding parameters were obtained by complex nonlinear least-squares (CNLLSQ) fitting. The complex impedance plots typical for investigated glasses consist of a high-frequency semicircle with the center below the real axis and low-frequency spur. The equivalent circuit that represents such depressed semicircle is a parallel combination of resistor $(R)$ and constant-phase element (CPE). The CPE is an empirical impedance function of the type $Z_{\mathrm{CPE}}{ }^{*}=A(j \omega)^{-\alpha}$, where $A$ and $\alpha$ are the constants. The values of the resistance obtained from the fitting procedures, $R$ 
and electrode dimensions ( $d$ is sample thickness; $A$ is electrode area) were used to calculate the dc conductivity, $\sigma_{\mathrm{dc}}=d /(R \times$ A).

\section{RESULTS}

3.1. Thermal Behavior. From dilatometric curves, the values of glass transition temperatures, $T_{\mathrm{g}}$, dilatation softening temperatures, $T_{\mathrm{d}}$, and the coefficients of thermal expansion, $\alpha$ $\left(150-250{ }^{\circ} \mathrm{C}\right)$, for the $40 \mathrm{Li}_{2} \mathrm{O}-10 \mathrm{~B}_{2} \mathrm{O}_{3}-(50-x) \mathrm{P}_{2} \mathrm{O}_{5}-$ $x \mathrm{GeO}_{2}$ glasses were determined. Their dependence on the $\mathrm{GeO}_{2}$ content is shown in Figure 1 and Table 1 . It can be seen

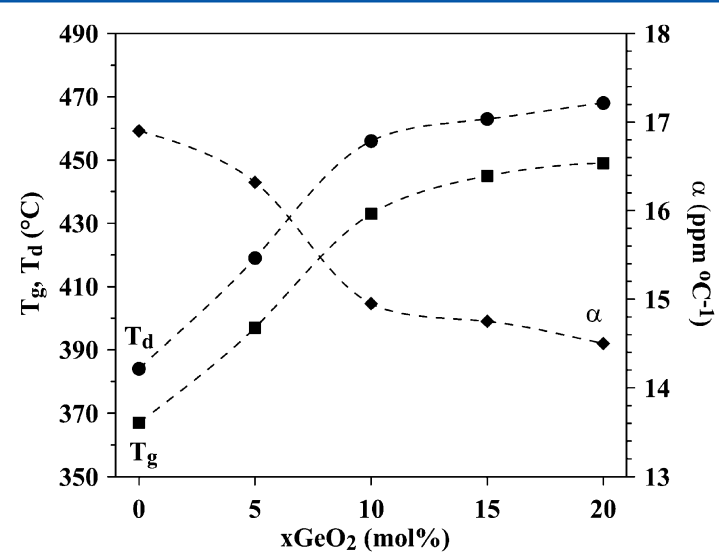

Figure 1. Compositional dependence of the glass transition temperature, $T_{\mathrm{g}}$, dilatometric softening temperature, $T_{\mathrm{d}}$, and thermal expansion coefficient, $\alpha$, of the $40 \mathrm{Li}_{2} \mathrm{O}-10 \mathrm{~B}_{2} \mathrm{O}_{3}-(50-x) \mathrm{P}_{2} \mathrm{O}_{5}-$ $x \mathrm{GeO}_{2}$ glasses determined by dilatometric measurements. The line is only a guide for the eye.

that the incorporation of $\mathrm{GeO}_{2}$ units into the phosphate glass network results in an increase of the $T_{\mathrm{g}}$ and $T_{\mathrm{d}}$ values, whereas the thermal expansion coefficient, $\alpha$, decreases. Steep increase in $T_{\mathrm{g}}$ and $T_{\mathrm{d}}$ and a decrease in $\alpha$ is observed for the concentration range of $x=0-10 \mathrm{~mol}_{\mathrm{GeO}}$, shown in Figure 1. Such a behavior is attributed to the increasing of bond strength in the glass network with increasing $\mathrm{GeO}_{2}$ content, which can be ascribed partly to the replacement of weaker $\mathrm{O}-\mathrm{P}$ bonds $\left(\mathrm{D}^{0}{ }_{298}(\mathrm{O}-\mathrm{P}) \approx 599 \mathrm{~kJ} \mathrm{~mol}^{-1}\right)$ by stronger $\mathrm{O}-\mathrm{Ge}$ bonds $\mathrm{D}^{0}{ }_{298}\left((\mathrm{O}-\mathrm{Ge}) \approx 659 \mathrm{~kJ} \mathrm{~mol}^{-1}\right)^{17}$ and also partly to the reticulation effect of germanium dioxide.

3.2. Structural Analysis: MAS NMR, Raman Spectroscopy. ${ }^{31} \mathrm{P}$ MAS NMR spectra of the $40 \mathrm{Li}_{2} \mathrm{O}-10 \mathrm{~B}_{2} \mathrm{O}_{3}-(50-$ $x) \mathrm{P}_{2} \mathrm{O}_{5}-x \mathrm{GeO}_{2}$ glasses are shown in Figure 2. The spectrum of the starting $40 \mathrm{Li}_{2} \mathrm{O}-10 \mathrm{~B}_{2} \mathrm{O}_{3}-50 \mathrm{P}_{2} \mathrm{O}_{5}$ glass contains two NMR signals, the main resonance centered at $-23.7 \mathrm{ppm}$ and the unresolved shoulder near $-34.9 \mathrm{ppm}$ assigned to $\mathrm{Q}^{1}$ and $\mathrm{Q}^{2}$ structural units, respectively. ${ }^{18}$ The ${ }^{31} \mathrm{P}$ MAS NMR spectra show significant shift to higher frequency within the composition region of $0-10 \mathrm{~mol} \% \mathrm{GeO}_{2}$, indicating a depolymerization of phosphate chains. The rapid increase in the number of $\mathrm{Q}^{1}$ and decrease of $\mathrm{Q}^{2}$ units can be correlated with the increase in the glass transition temperature, $T_{g}$, and decrease in coefficient of thermal expansion, $\alpha$, as a result of interconnection between depolymerized phosphate chains and germanate units, which do not enter the phosphate network. In contrast in the compositional range of $15-25 \mathrm{~mol} \% \mathrm{GeO}_{2}$, the germanium units start to enter into phosphate structure, which favors the formation of more $Q^{1}$ units. ${ }^{19}$

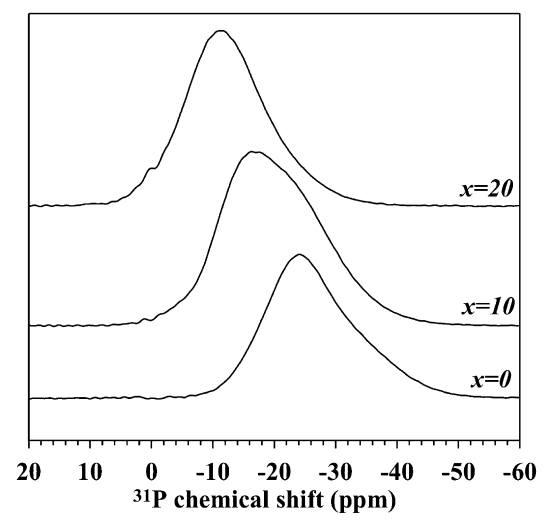

Figure 2. ${ }^{31} \mathrm{P}$ MAS NMR spectra of the $40 \mathrm{Li}_{2} \mathrm{O}-10 \mathrm{~B}_{2} \mathrm{O}_{3}-(50-$ $x) \mathrm{P}_{2} \mathrm{O}_{5}-x \mathrm{GeO}_{2}$ glasses.

Figure 3 exhibits the ${ }^{11} \mathrm{~B}$ MAS NMR spectra of the $40 \mathrm{Li}_{2} \mathrm{O}-$ $10 \mathrm{~B}_{2} \mathrm{O}_{3}-(50-x) \mathrm{P}_{2} \mathrm{O}_{5}-x \mathrm{GeO}_{2}$ glasses. The spectrum of base

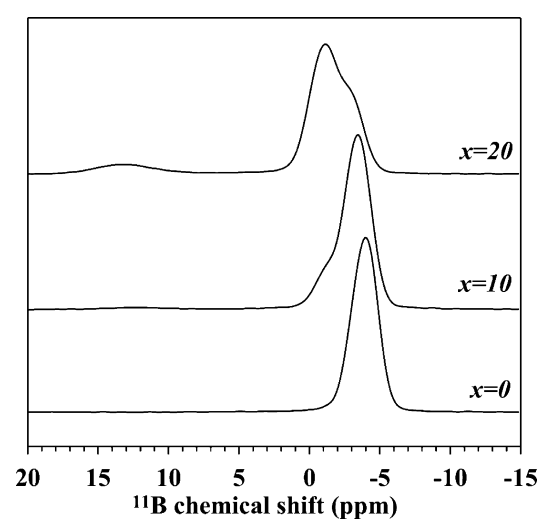

Figure 3. ${ }^{11} \mathrm{~B}$ MAS NMR spectra of the $40 \mathrm{Li}_{2} \mathrm{O}-10 \mathrm{~B}_{2} \mathrm{O}_{3}-(50-$ $x) \mathrm{P}_{2} \mathrm{O}_{5}-x \mathrm{GeO}_{2}$ glasses.

glass, free of $\mathrm{GeO}_{2}$, exhibits a single symmetrical resonance at $-3.9 \mathrm{ppm}$, characteristic for $\mathrm{BO}_{4}$ units coordinated by four phosphorus atoms. ${ }^{20}$ With the addition of $\mathrm{GeO}_{2}$, the ${ }^{11} \mathrm{~B}$ NMR spectra are modified. A second $\mathrm{BO}_{4}$ resonance appears in the region of $-1.3 \mathrm{ppm}$, probably due to the formation of mixed $\mathrm{B}(\mathrm{OP})_{4-x}(\mathrm{OGe})_{x}$ units. Moreover, in glasses containing more than $15 \mathrm{~mol} \%$ of $\mathrm{GeO}_{2}$ a broad signal in the $10-16 \mathrm{ppm}$ region is related to the presence of trigonal $\mathrm{BO}_{3}$ units as can be seen in Table $2 .^{20}$

Figure 4 reveals the evolution of Raman spectra of the $40 \mathrm{Li}_{2} \mathrm{O}-10 \mathrm{~B}_{2} \mathrm{O}_{3}-(50-x) \mathrm{P}_{2} \mathrm{O}_{5}-x \mathrm{GeO}_{2}$ glasses showing a consistency with the results of NMR spectra and supporting above analysis. The Raman bands are assigned in accordance with literature data obtained for the previously studied germanophosphate glasses. ${ }^{16,21-23}$ The most important changes in Raman spectra appeared in both high-frequency region, $1000-1300 \mathrm{~cm}^{-1}$, and middle-frequency range, 500$700 \mathrm{~cm}^{-1}$. The band at $1169 \mathrm{~cm}^{-1}$ for $\mathrm{GeO}_{2}$-free glass is associated with the symmetric, $\nu_{\mathrm{s}}\left(\mathrm{PO}_{2}\right)$, stretching mode of nonbridging oxygen in $\mathrm{Q}^{2}$ units. The band at $1260 \mathrm{~cm}^{-1}$ is related to the asymmetric, $\nu_{\text {as }}\left(\mathrm{PO}_{2}\right)$, stretching mode in $\mathrm{Q}^{2}$ units, whereas at lower frequency, a very weak band at about $1100 \mathrm{~cm}^{-1}$ suggests the traces of the $\nu_{\mathrm{s}}\left(\mathrm{PO}_{3}\right)$ in $\mathrm{Q}^{1}$ units. The spectrum in the middle range shows the bands at 703 and 665 $\mathrm{cm}^{-1}$, which have been assigned to the symmetric stretching mode of $\mathrm{P}-\mathrm{O}-\mathrm{P}$ bridging bond in $\mathrm{Q}^{1}$ and $\mathrm{Q}^{2}$ structure, 
Table 2. Deconvolution Results of the ${ }^{11} \mathrm{~B}$ MAS NMR Spectra of the $40 \mathrm{Li}_{2} \mathrm{O}-10 \mathrm{~B}_{2} \mathrm{O}_{3}-(50-x) \mathrm{P}_{2} \mathrm{O}_{5}-x \mathrm{GeO}_{2}$ Glasses

\begin{tabular}{|c|c|c|c|c|c|c|c|c|c|}
\hline \multirow[b]{2}{*}{$\mathrm{GeO}_{2}(\mathrm{~mol} \%)$} & \multicolumn{3}{|c|}{$\mathrm{B}(\mathrm{OP})_{4}$} & \multicolumn{3}{|c|}{$\mathrm{B}(\mathrm{OP})_{3} \mathrm{OGe}$} & \multicolumn{3}{|c|}{$\mathrm{BO}_{3}$} \\
\hline & $\delta(\mathrm{ppm})$ & fwhm & $\%$ & $\delta(\mathrm{ppm})$ & fwhm & $\%$ & $\delta(\mathrm{ppm})$ & fwhm & $\%$ \\
\hline 0 & -3.9 & 2.2 & 100 & & & & & & \\
\hline 10 & -3.5 & 2.1 & 82 & -1.3 & 2.1 & 18 & & & \\
\hline 20 & -3.2 & 1.8 & 22 & -1.1 & 2.6 & 71 & 13.2 & 4.0 & 7 \\
\hline
\end{tabular}

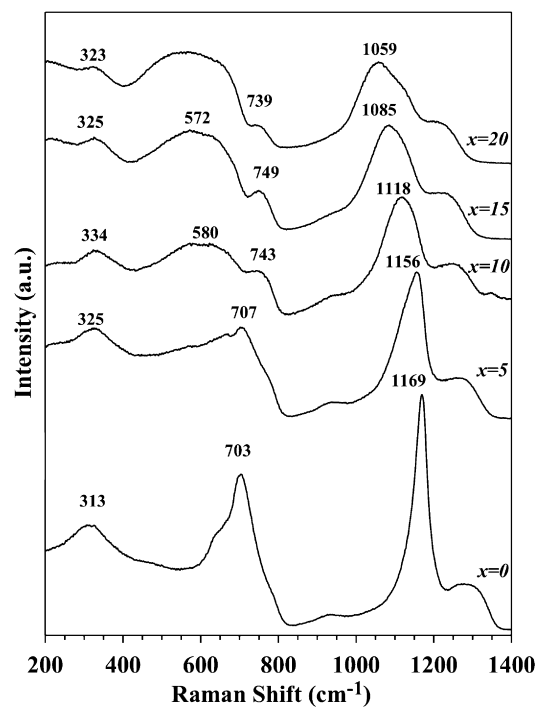

Figure 4. Raman spectra of the $40 \mathrm{Li}_{2} \mathrm{O}-10 \mathrm{~B}_{2} \mathrm{O}_{3}-(50-x) \mathrm{P}_{2} \mathrm{O}_{5}-$ $x \mathrm{GeO}_{2}$ glasses.

respectively. Addition of $\mathrm{GeO}_{2}$ significantly changes Raman spectra revealing progressive depolymerization of phosphate chains. The bands related to the $\nu_{s}\left(\mathrm{PO}_{2}\right)$ symmetric stretching frequency in $\mathrm{Q}^{2}$ metaphosphate chains are replaced by diphosphate $Q^{1}$ units at $1085 \mathrm{~cm}^{-1}$. However, even at lower $\mathrm{GeO}_{2}$ content, up to $10 \mathrm{~mol} \%$, barely detectable incorporation of germanate units into phosphate network can be evidenced by the featureless broad bands at $540-650 \mathrm{~cm}^{-1}$. With further increase of $\mathrm{GeO}_{2}$, the better defined bands appeared at 571 and $642 \mathrm{~cm}^{-1}$. These bands are related to the germanium units, $\mathrm{GeO}_{4}$ and $\mathrm{GeO}_{6}$, which are incorporated into the phosphate network suggesting the formation of $\mathrm{P}-\mathrm{O}-\mathrm{Ge}$ bonds (Figure 4). Moreover, the strength and intensity of bands assigned to phosphate units decrease, leading to the conclusion that more germanium units are involved in glass network as a glass former.
It should also be noted that at low boron content the borate vibrational modes are difficult to discern because of the great spectral overlap. In contrast, it appears that the Raman scattering cross section of the phosphate structural groups is significantly greater than of the borate structural groups because borate content is low and the spectral intensity is dominated by the phosphate structural units.

3.3. Electrical Properties. Electrical properties of glasses in the compositional series $40 \mathrm{Li}_{2} \mathrm{O}-10 \mathrm{~B}_{2} \mathrm{O}_{3}-(50-x) \mathrm{P}_{2} \mathrm{O}_{5}-$ $x \mathrm{GeO}_{2}, x=0-25 \mathrm{~mol} \%$, were investigated by impedance spectroscopy. Complex impedance plots for the $\mathrm{Ge}-15$ glass measured at different temperatures are shown in Figure 5. The impedance plot measured at $213 \mathrm{~K}$ consists of a single semicircle, whereas plots measured at a higher temperature $(333 \mathrm{~K})$ consist of a high-frequency semicircle related to the bulk behavior and a low-frequency spur that emanates from electrode polarization. The $x$ intercept of the semicircle represents the value of the dc resistance, $R$, observed at a certain temperature. Because the radius of the semicircle related to the bulk behavior decreases with increasing temperature, it should be concluded that the ion conduction is thermally activated.

Figure 6 shows the complex impedance plots for all investigated glasses measured at $303 \mathrm{~K}$. For glasses with low
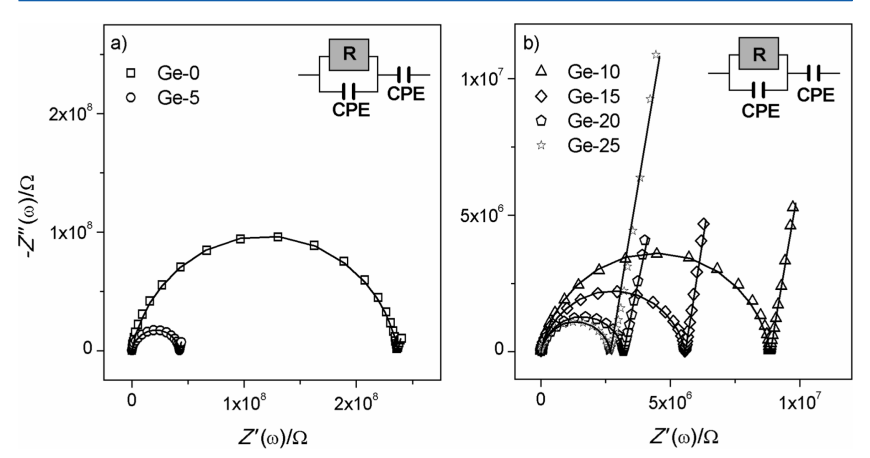

Figure 6. Complex impedance plots for the $40 \mathrm{Li}_{2} \mathrm{O}-10 \mathrm{~B}_{2} \mathrm{O}_{3}-(50-$ $x) \mathrm{P}_{2} \mathrm{O}_{5}-x \mathrm{GeO}_{2}$ glasses measured at $303 \mathrm{~K}$.
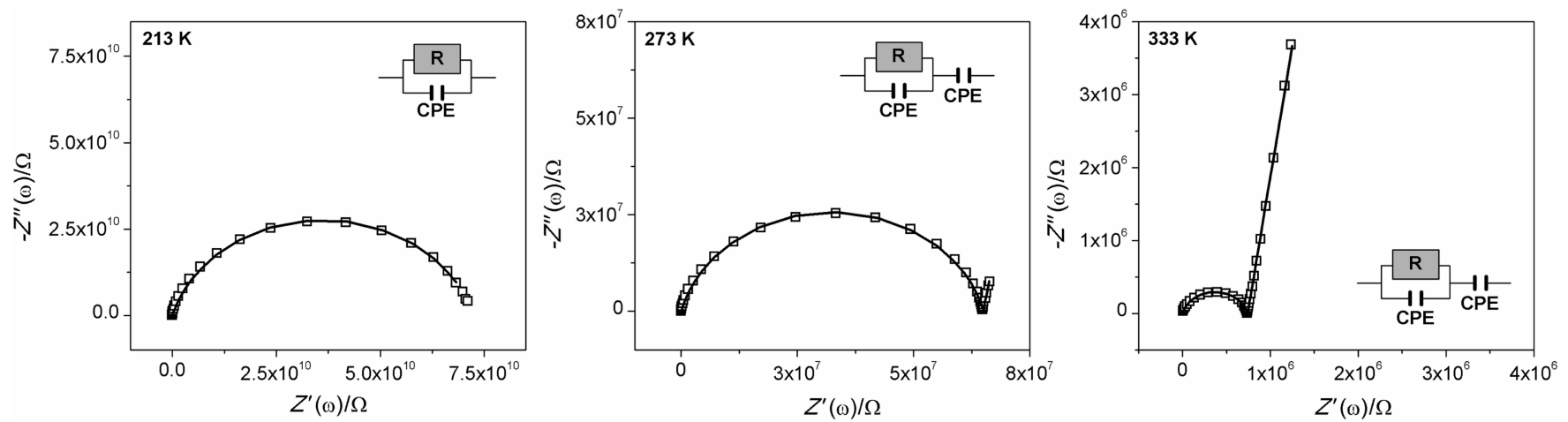

Figure 5. Complex impedance plots for the Ge-15 glass measured at different temperatures. 
$\mathrm{GeO}_{2}$ content up to $5 \mathrm{~mol} \%$ (Figure $6 \mathrm{a}$ ), the impedance plots exhibit a single semicircle, whereas for glasses with increasing $\mathrm{GeO}_{2}$ content, the low-frequency spur additionally appeared in the impedance spectra, which is typical for the ion-conducting glasses.

The parameters of equivalent circuits modeling were determined by complex nonlinear least-squares fitting (CNLLSF) of the experimental impedance data. Experimental data are in excellent agreement with theoretical curves obtained by fitting using commercial software (ZView) as can be seen in Figures 5 and 6 . The values of the dc conductivity, $\sigma_{\mathrm{dc}}$ listed in Table 1 were calculated using the $\sigma_{\mathrm{dc}}=d /(R \times A)$ equation.

The activation energies for dc conductivity, $E_{\mathrm{do}}$ for each glass were determined from the slope of $\log \sigma_{\mathrm{dc}} T$ versus $1 / T$ using the equation $\sigma_{\mathrm{dc}} T=\sigma_{0} \exp \left(-E_{\mathrm{dc}} / k_{\mathrm{B}} T\right)$, where $\sigma_{\mathrm{dc}}$ is the $\mathrm{dc}$ conductivity, $\sigma_{0}$ is the pre-exponent, $k_{\mathrm{B}}$ is the Boltzmann constant, and $T$ is the temperature. The temperature dependency plots of the $\mathrm{dc}$ conductivity, $\sigma_{\mathrm{dc}}$ from which activation energies were calculated, are shown in Figure 7. The corresponding activation energy values for all glasses investigated are listed in Table 1.

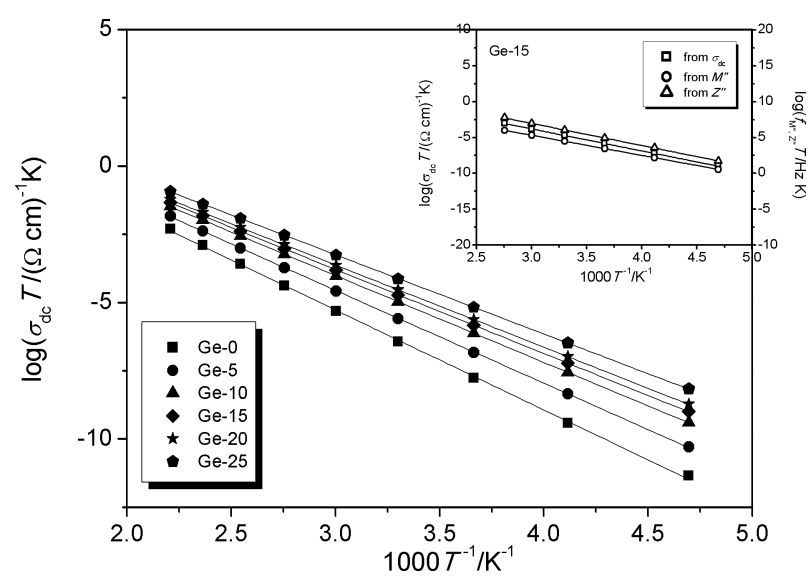

Figure 7. Temperature dependence of the dc conductivity, $\sigma_{\mathrm{d} \text {, }}$ for all $40 \mathrm{Li}_{2} \mathrm{O}-10 \mathrm{~B}_{2} \mathrm{O}_{3}-(50-x) \mathrm{P}_{2} \mathrm{O}_{5}-x \mathrm{GeO}_{2}$ glasses. Inset: Temperature dependence of the dc conductivity, $\sigma_{\mathrm{dc}}$ and the relaxation frequencies, $f_{M^{\prime \prime}}$ and $f_{Z^{\prime \prime}}$ for Ge-15 glass.

Compositional dependence of dc conductivity, $\sigma_{\mathrm{dc}}$ at $303 \mathrm{~K}$ and activation energy, $E_{\mathrm{dc}}$ for the $40 \mathrm{Li}_{2} \mathrm{O}-10 \mathrm{~B}_{2} \mathrm{O}_{3}-(50-$ $x) \mathrm{P}_{2} \mathrm{O}_{5}-x \mathrm{GeO}_{2}, x=0-25 \mathrm{~mol} \%$, glasses are shown in Figure 8. As can be seen, the dc conductivity, $\sigma_{\mathrm{dc}}$, increases, whereas the activation energy, $E_{\mathrm{dc}}$, values decrease continuously with increasing $\mathrm{GeO}_{2}$ content in the glass network. The most pronounced increase in dc conductivity for more than 1 order of magnitude is observed between $\mathrm{GeO}_{2}$-free glass and glass containing $10 \mathrm{~mol} \%$ of $\mathrm{GeO}_{2}$. In contrast, further addition of $\mathrm{GeO}_{2}$ for glasses containing between 15 and $25 \mathrm{~mol} \% \mathrm{GeO}_{2}$ exhibits an increase in dc conductivity for just $1 / 2$ order of magnitude, suggesting different electrical transport behavior. Because the lithium ion content is being held constant, such behavior can be attributed solely to the structural modifications caused by $\mathrm{GeO}_{2}$ addition and depolymerization of phosphate chains.

To clarify the electrical transport in these glasses, the frequency dependence of the ac conductivity at different temperatures for Ge-15 is shown in Figure 9. According to the Jonscher's power low, ${ }^{24}$ the conductivity dispersion in glasses is described by $\sigma(\omega)=\sigma_{\mathrm{dc}}+A \omega^{s}$, where $A$ is the proportionality

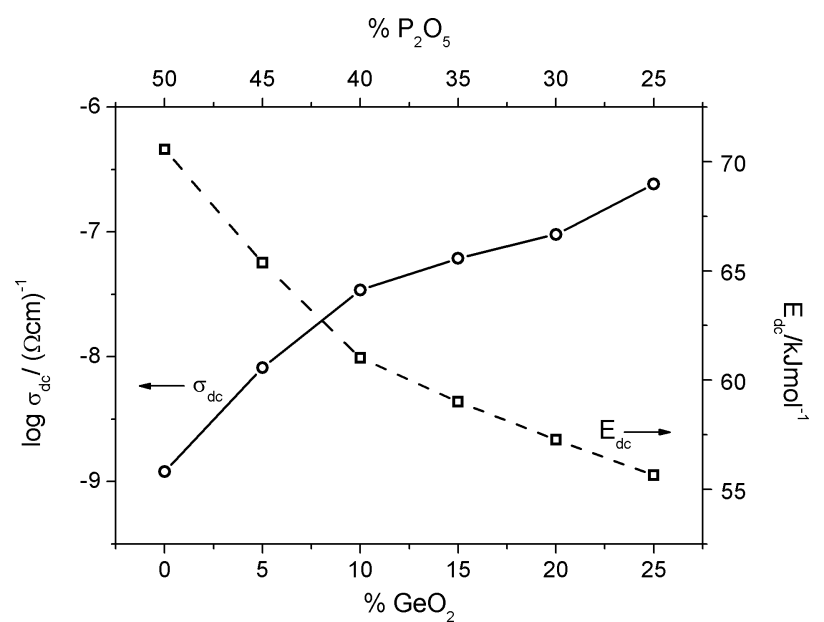

Figure 8. Compositional dependence of dc conductivity, $\sigma_{\mathrm{dc}}$ at $303 \mathrm{~K}$ and activation energy, $E_{\mathrm{d} o}$ for the $40 \mathrm{Li}_{2} \mathrm{O}-10 \mathrm{~B}_{2} \mathrm{O}_{3}-(50-x) \mathrm{P}_{2} \mathrm{O}_{5}-$ $x \mathrm{GeO}_{2}$ glasses.

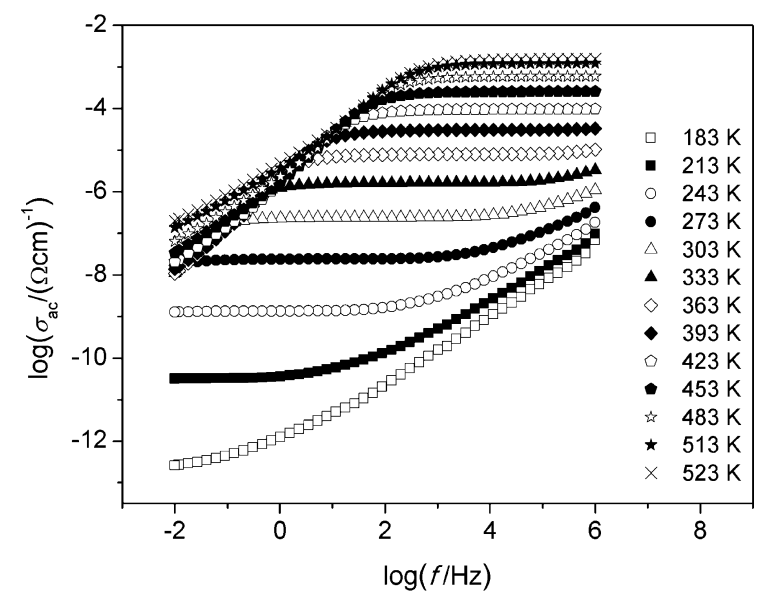

Figure 9. Frequency dependence of the ac conductivity, $\sigma_{\mathrm{ac}}$ for the Ge-15 glass measured at different temperatures.

constant, which determines the strength of polarizability, whereas $s$ is the power low exponent and represents the degree of interaction between mobile ions and the network. Figure 9 shows an evolution of the frequency and temperature dependence of ac conductivity that is typical for most ionconducting glasses. At low frequency and sufficiently high temperature, the plateau that corresponds to the $\mathrm{dc}$ conductivity appeared. With further increase of the temperature, the dc plateau is shifted to the higher frequencies accompanied by the drop in conductivity related to the electrode polarization. The electrode polarization effect is related to the presence of metallic electrodes, which block the ions' motion resulting in the accumulation of mobile ions near the electrodes, leading to the formation of space-charge layers. The voltage drops rapidly in these layers, leading to the decrease of the ac conductivity at low frequency. It is clear from Figure 9 that the investigated glasses display the dispersive behavior at low temperature and high frequencies. Also, the universal power low dependence of ac conductivity on frequency can be correlated to the Almond-West (AW) ${ }^{25,26}$ back-and-forth formalism. The correlated back-and-forth motion leads to the dispersive part of ionic conductivity at higher frequencies, whereas the long-term ion transport is 
related to the low-frequency plateau resulting in the $\mathrm{dc}$ conductivity. ${ }^{27,28}$

The variation in exponent $s$ as a function of temperature and addition of $\mathrm{GeO}_{2}$ is depicted in Figure 10. Usually, the

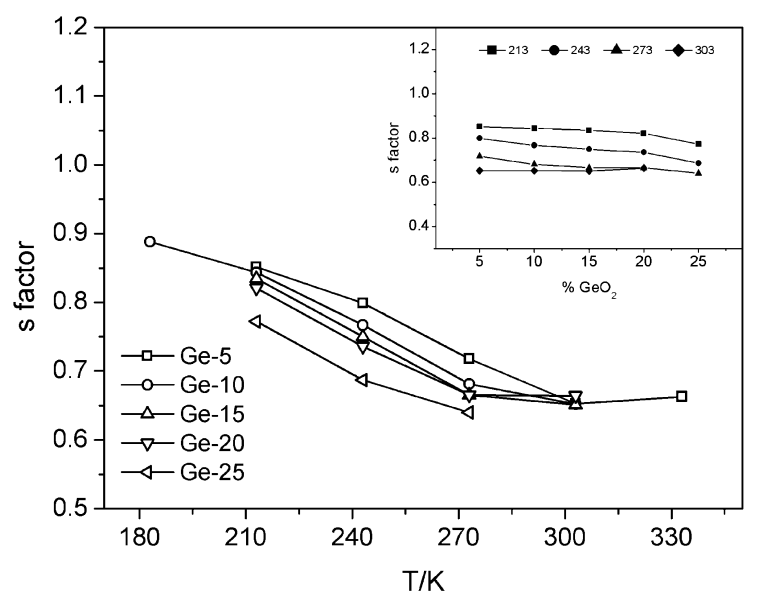

Figure 10. Variation in factor $s$ as a function of temperature. Inset: the variation of factor $s$ with addition of $\mathrm{GeO}_{2}$.

conductivity mechanism can be understood from the temperature dependence behavior of $s$. The values for exponent $s$ at the constant temperature do not vary significantly with the addition of $\mathrm{GeO}_{2}$ content as can be seen in inset to Figure 10. In contrast, for $40 \mathrm{Li}_{2} \mathrm{O}-10 \mathrm{~B}_{2} \mathrm{O}_{3}-(50-x) \mathrm{P}_{2} \mathrm{O}_{5}-x \mathrm{GeO}_{2}$ glasses the exponent $s$ decreases with increasing temperature, showing that at lower temperature the ionic motion is less activated. The process at higher temperatures is related to the ionic relaxation, and at about $270 \mathrm{~K}$, the exponent $s$ has a value $s=0.65 \pm 0.04 .^{29}$

3.4. Dielectric Properties. Impedance data of the glasses investigated in this study have been analyzed using two additional approaches: complex permittivity and electrical modulus formalism.

The complex permittivity is defined as

$$
\varepsilon^{*}(\omega)=\frac{1}{i \omega C_{0} Z^{*}}=\varepsilon^{\prime}(\omega)-i \varepsilon^{\prime \prime}(\omega)
$$

where $\varepsilon^{\prime}(\omega)$ and $\varepsilon^{\prime \prime}(\omega)$ are the real and imaginary parts of the complex permittivity. Frequency dependence of $\varepsilon^{\prime}(\omega)$, known as a dielectric permittivity, for Ge-15 glass measured at different temperatures is shown in Figure 11a, and the values of $\varepsilon^{\prime}(\omega)$ measured at $303 \mathrm{~K}$ and $11.7 \mathrm{~Hz}$ for all glasses studied are listed in Table 3. At higher frequencies, because of rapid polarization processes occurring in the glasses under applied field, the dielectric permittivity approaches a constant value, $\varepsilon_{\infty}{ }^{\prime}(\omega)$, as can be seen in Figure 11b. The low-frequency dispersion of $\varepsilon^{\prime}(\omega)$ increases with increasing temperature as a result of an increase in electrode polarization. In contrast, the dielectric dispersion shifts toward higher frequencies as temperature rises. Because the ions are blocked by the metal electrodes, the electrical field sharply decreases in the glass bulk at low frequency, which implies a significant bulk electrical polarization and an increase of the dielectric permittivity. ${ }^{27}$ In contrast, the electrode polarization is significant at higher temperatures and sometimes can mask the bulk response of glasses in the low-frequency region. However, for the glasses investigated, the low-frequency plateau, denoted as the static

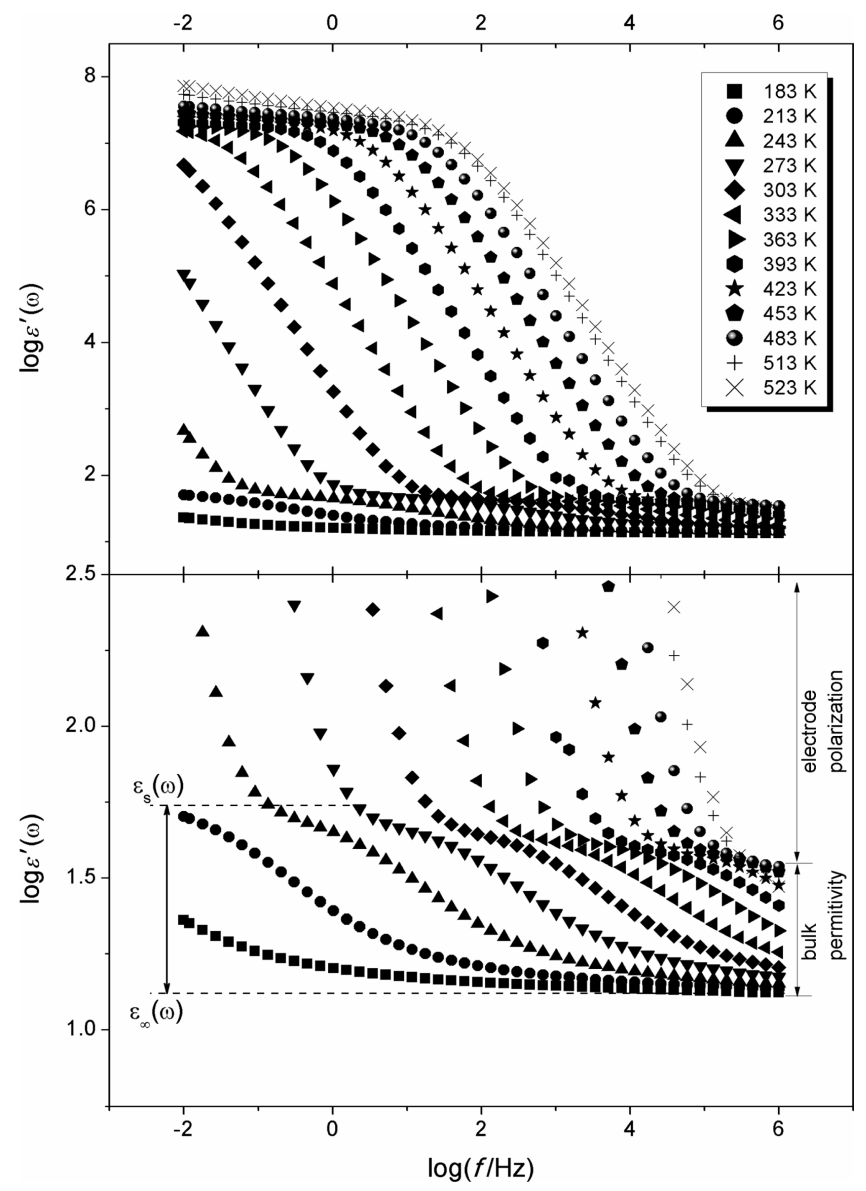

Figure 11. (a) Frequency dependence of dielectric constant, $\varepsilon^{\prime}(\omega)$ for Ge-15 glass measured at different temperatures; (b) rescaled $y$ axis.

value, $\varepsilon_{\mathrm{s}}{ }^{\prime}(\omega)$, is observed by rescaling the $y$ axis, which allows the separation of the bulk permittivity from the electrode polarization (Figure $11 \mathrm{~b}$ ). The static permittivity, $\varepsilon_{s}{ }^{\prime}(\omega)$, is usually attributed to bulk polarization effects due to long-range hopping of mobile ions with respect to the immobile glass matrix in the ionic glasses.

The resulting ionic contribution to the dielectric permittivity can be given by $\Delta \varepsilon^{\prime}=\varepsilon_{\mathrm{s}}{ }^{\prime}(\omega)-\varepsilon_{\infty}{ }^{\prime}(\omega),{ }^{30,31}$ where $\Delta \varepsilon^{\prime}$ is the dielectric strength that represents the magnitude of permittivity change due to the ionic relaxation.

Figure 12 shows a dependence of $\Delta \varepsilon^{\prime}$ upon the $\mathrm{GeO}_{2}$ content at 243 and $273 \mathrm{~K}$. The values for $\Delta \varepsilon^{\prime}$ first increase for glasses containing up to $15 \% \mathrm{GeO}_{2}$ and then decrease with increasing $\mathrm{GeO}_{2}$ content. Because $\Delta \varepsilon^{\prime}$ is a variable that depends on the mobility of ions, the changes in $\Delta \varepsilon^{\prime}$ behavior are related to the hopping dynamics of mobile lithium ions.

The electric modulus is defined as the reciprocal of the complex permittivity:

$$
M^{*}(\omega)=\frac{1}{\varepsilon^{*}(\omega)}=M^{\prime}(\omega)+i M^{\prime \prime}(\omega)
$$

The great advantage in using the electric modulus formalism for electrical relaxation analysis is the diminution of polarization effects. ${ }^{32}$ Frequency dependence of normalized imaginary part of electrical modulus, $M^{\prime}(\omega)^{\prime}$, for Ge-15 sample at selected temperatures is shown in Figure 13. The maximum of the $M^{\prime \prime}(\omega)$ peak corresponds to relaxation frequency, $f_{M^{\prime \prime}}=$ $\left(2 \pi \tau_{M^{\prime \prime}}\right)^{-1}$, where $\tau_{M^{\prime \prime}}$ is the relaxation time. The relaxation 
Table 3. Selected Dielectric Properties for the $40 \mathrm{Li}_{2} \mathrm{O}-10 \mathrm{~B}_{2} \mathrm{O}_{3}-(50-x) \mathrm{P}_{2} \mathrm{O}_{5}-x \mathrm{GeO}_{2}, x=0-25 \mathrm{~mol} \%$, Glasses

\begin{tabular}{lcccc} 
sample & $\varepsilon^{\prime}(\omega)$ at $303 \mathrm{~K}$ and $11.7 \mathrm{~Hz}$ & $\tau_{M^{\prime \prime}}$ at $303 \mathrm{~K}(\mathrm{~s})$ & $\tau_{\mathrm{Z}^{\prime \prime}}$ at $303 \mathrm{~K}(\mathrm{~s})$ & $E_{M^{\prime \prime}}( \pm 0.5 \%)\left(\mathrm{kJ} \mathrm{mol}{ }^{-1}\right)$ \\
Ge-0 & 27.00 & $7.96 \times 10^{-4}$ & $1.54 \times 10^{-3}$ & 65.60 \\
$\mathrm{Ge}-5$ & 36.12 & $1.26 \times 10^{-4}$ & $2.96 \times 10^{-4}$ & 59.71 \\
$\mathrm{Ge}-10$ & 44.92 & $3.02 \times 10^{-5}$ & $7.05 \times 10^{-5}$ & 55.80 \\
$\mathrm{Ge}-15$ & 67.63 & $1.81 \times 10^{-5}$ & $4.43 \times 10^{-5}$ & 53.62 \\
$\mathrm{Ge}-20$ & 121.32 & $1.14 \times 10^{-5}$ & $2.98 \times 10^{-5}$ & 53.74 \\
$\mathrm{Ge}-25$ & 720.38 & $5.90 \times 10^{-6}$ & $1.03 \times 10^{-5}$ & 52.54 \\
\hline
\end{tabular}

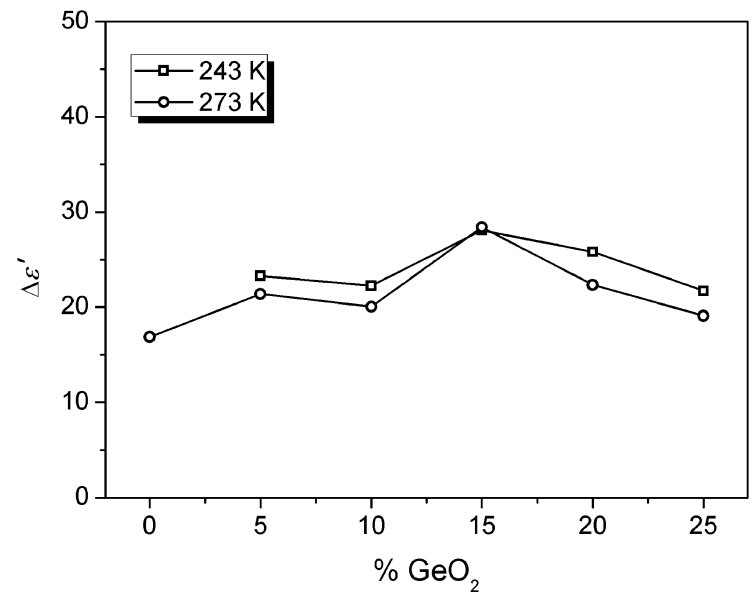

Figure 12. Dependence of $\Delta \varepsilon^{\prime}$ upon the $\mathrm{GeO}_{2}$ content at two different temperatures, 273 and $243 \mathrm{~K}$.

maximum shifts to higher frequencies with increasing temperature, suggesting a thermally activated behavior. The relaxation time values, $\tau_{M^{\prime \prime}}$, determined from the peak maxima positions, are listed in Table 3 and decrease with increasing the $\mathrm{GeO}_{2}$ content.

For comparison, the frequency dependence of normalized imaginary part of impedance, $Z^{\prime \prime}(\omega)$, for Ge-15 sample at selected temperatures can be seen in Figure 13. Peak maximum shifts to higher frequencies with increasing temperature and is only slightly shifted with respect to $M^{\prime \prime}(\omega)$ peak maximum position. Relaxation time values, $\tau_{Z^{\prime \prime}}$, were determined the same as for $\tau_{M^{\prime \prime}}$ from relaxation frequency using equation $\tau_{Z^{\prime \prime}}=$ $\left(2 \pi \mathrm{f}_{Z^{\prime \prime}}\right)^{-1}$. The relaxation time values, $\tau_{Z^{\prime \prime}}$, listed in Table 3 , are in good accordance with $\tau_{M^{\prime \prime}}$, indicating a single relaxation process observed in both $M^{\prime \prime}(\omega)$ and $Z^{\prime \prime}(\omega)$ plots.

Finally, temperature dependence of the dc conductivity, $\sigma_{\mathrm{d} c}$ and the relaxation frequencies, $f_{M^{\prime \prime}}$ and $f_{Z^{\prime \prime}}$, for Ge-15 glass are shown in the inset of Figure 7. Activation energies for electrical relaxation, $E_{M^{\prime \prime}}$ and $E_{Z^{\prime \prime}}$, were determined for all glasses from the slopes of $\log \left(f_{M^{\prime \prime}} T\right)$ and $\log \left(f_{Z^{\prime \prime}} T\right)$ versus $1 / T$ using the Arrhenius equations $f_{M^{\prime \prime}} T=f_{0 \mathrm{M}^{\prime \prime}} \exp \left(-E_{M^{\prime \prime}} / k_{\mathrm{B}} T\right)$ and $f_{Z^{\prime \prime}} T=$ $f_{0 \mathrm{z}^{\prime \prime}} \exp \left(-E_{\mathrm{Z}^{\prime \prime}} / \mathrm{k}_{\mathrm{B}} T\right)$, respectively, where $\sigma_{\mathrm{dc}} T=\sigma_{0} \exp \left(-E_{\mathrm{dc}} /\right.$ $\mathrm{k}_{\mathrm{B}} T$ ). The values of activation energies, $E_{M^{\prime \prime}}$ and $E_{Z^{\prime \prime}}$, listed in Table 3, are in good accordance with activation energy for the $\mathrm{dc}$ conductivity, $E_{\mathrm{d} o}$ suggesting the close agreement between relaxation processes and dc conductivity.

\section{DISCUSSION}

The evolution of the Raman spectra exhibits the transformation of $\mathrm{Q}^{2}$ metaphosphate chains to $\mathrm{Q}^{1}$ pyrophosphate units indicating depolymerization as the $\mathrm{GeO}_{2}$ content is increased. It seems that the modification of phosphate network is mostly caused by the network modifier especially at lower $\mathrm{GeO}_{2}$ content, up to $10 \mathrm{~mol} \%$. In this compositional range, the

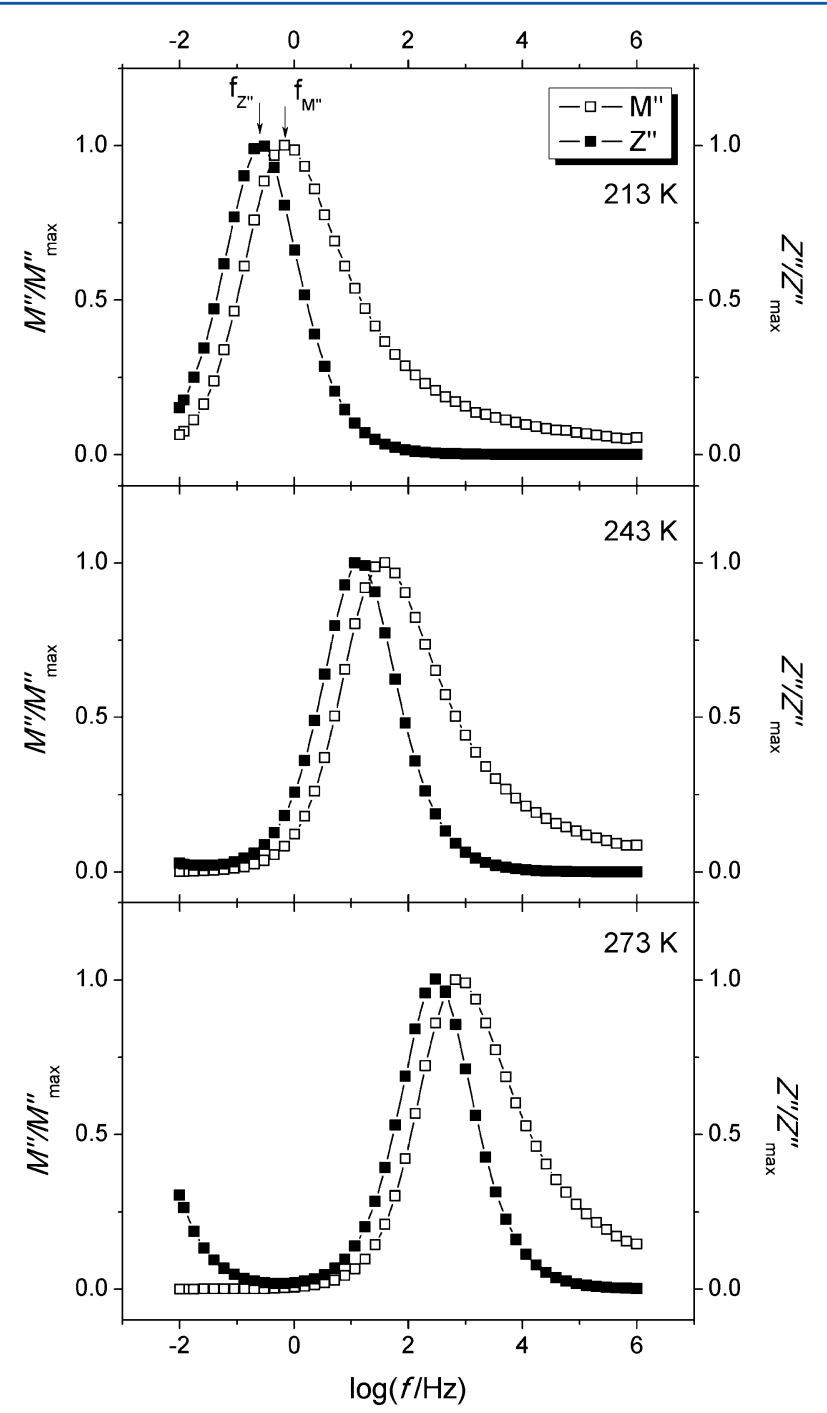

Figure 13. Frequency dependence of normalized imaginary part of electrical modulus, $M^{\prime \prime}(\omega)$ (open symbol), and impedance, $Z^{\prime \prime}$, (full symbol), for Ge-15 glass.

rapid increase of $T_{\mathrm{g}}$ (Figure 1) can be explained by the crosslinkage of the polyphosphate chains and $\mathrm{GeO}_{2}$ units. It is worth mentioning that at low $\mathrm{GeO}_{2}$ content the structure predominantly consists of polyphosphate chains and fourcoordinated germanium units, ${ }^{14,33}$ but some higher coordinated germanium units, such as $\mathrm{GeO}_{6}$ and $\mathrm{GeO}_{5}$, could be also present in the glass structure. Thus, the structure could be visualized as an interconnection between meta- and pyrophosphate units and slightly negatively charged $\mathrm{GeO}_{4}$ units. Therefore, the rapid increase in $T_{\mathrm{g}}$ for glasses containing up to $10 \mathrm{~mol} \% \mathrm{GeO}_{2}$ can be explained in terms of the formation of cross-linked structural units resulting in more closely packed 
glass structure with improved thermal stability. These observations are in good agreement with the spectroscopic studies for ternary germanophosphate glasses. ${ }^{33}$

As the $\mathrm{GeO}_{2}$ content increases, the $\mathrm{P}-\mathrm{O}-\mathrm{P}$ bonds are replaced by the $\mathrm{P}-\mathrm{O}-\mathrm{Ge}$ linkages, which confirms the reactivity between germanium and phosphate units in the glass structure. Additionally, glasses containing up to $25 \mathrm{~mol} \%$ $\mathrm{GeO}_{2}$ content show well-defined bands at about 571 and 642 $\mathrm{cm}^{-1}$ related to the $\mathrm{GeO}_{4}$ and $\mathrm{GeO}_{6}$ units, respectively (Figure 4). However, the presence of some germanate rings in the glass network cannot be excluded, as indicated by the band at 478 $\mathrm{cm}^{-1}$. Also, the distinct bands at 681 and $754 \mathrm{~cm}^{-1}$ attributed to the $\mathrm{Q}^{1}$ units are consistent with a preferential modification of the phosphate over germanate units. ${ }^{33-35}$ An excellent agreement with the ${ }^{31} \mathrm{P}$ MAS NMR spectra confirms the shortening of phosphate chains that leads to the formation of more nonbridging oxygens in the glass structure. Although the concentration of $\mathrm{B}_{2} \mathrm{O}_{3}$ was kept constant at $10 \mathrm{~mol} \%$, for glasses containing more than $20 \mathrm{~mol} \% \mathrm{GeO}_{2}$, the ${ }^{11} \mathrm{~B}$ MAS NMR spectra indicate a presence of some trigonal $\mathrm{BO}_{3}$ units that are preferentially linked to the tetra-coordinated boron, $\mathrm{BO}_{4}{ }^{16}$ as exhibited in Figure 3 and Table 2.

The ionic conductivity for this series of glasses increases with the addition of $\mathrm{GeO}_{2}$. However, the rapid increase in conductivity for almost 2 orders of magnitude appears for glasses containing up to $10 \mathrm{~mol} \% \mathrm{GeO}_{2}$. Further addition of $\mathrm{GeO}_{2}$ up to $25 \mathrm{~mol} \%$ causes a slight increase in conductivity for less than 1 order of magnitude, suggesting a reduction in ionic motion. It should be pointed out that the compositional limit for obtaining noncrystalline glass samples is $25 \mathrm{~mol} \%$ $\mathrm{GeO}_{2}$ for this series of glasses. In contrast, because lithium ions concentration is kept constant, our attention was turned to the structural modifications responsible for such a behavior in electrical conductivity. It was reported ${ }^{14,16,33}$ that the structure of germanophosphate glasses with low $\mathrm{GeO}_{2}$ content is predominantly composed of metaphosphate chains with some barely detectable pyrophosphate units. Therefore, the lowest conductivity, observed for the Ge- 0 , is attributed to the lowest $\mathrm{Li}^{+}$ion mobility, indicating that the structure composed of polyphosphate chains hinders the $\mathrm{Li}^{+}$ions motion. It seems that the metaphosphate units play a role as deep Coulomb traps where $\mathrm{Li}^{+}$ions are bound to the discrete terminal nonbridging oxygens. ${ }^{15,36}$ Addition of $\mathrm{GeO}_{2}$ up to $10 \mathrm{~mol} \%$ indicates changes in the glass network, formation of the pyrophosphate units, and interconnection with $\mathrm{GeO}_{2}$ units. However, even a slight incorporation of the $\mathrm{GeO}_{2}$ units cannot be neglected. Consequently, the addition of $\mathrm{GeO}_{2}$ leads to the oxygen bonds rupturing, which decreases the connectivity of the phosphate network and increases the $\mathrm{Li}^{+}$ions mobility. Also, it was previously reported ${ }^{14,16,33}$ that at the low $\mathrm{GeO}_{2}$ content the germanium is tetrahedrally coordinated, $\mathrm{GeO}_{4}$, where one oxygen atom behaves as a nonbridging. Thus, the $\mathrm{Li}^{+}$ions are shared between two glass-former units where $\mathrm{Li}^{+}$ions are involved in the charge compensation of both pyrophosphate units and $\left[\mathrm{GeO}_{4}\right]^{-}$units whose charge is more delocalized, and $\mathrm{Li}^{+}$ions are less tightly bound probably because of the smaller binding energy of the $\mathrm{Li}^{+}$ions. Such a delocalization of charge could decrease a Coulombic energy of nonbringing oxygens, which in turns reduces the charge effectiveness leading to easier movement of $\mathrm{Li}^{+}$ions to the next compensation site. Moreover, it is well-known that the increase in the amount of the pyrophosphate units increases the number of nonbridging oxygens resulting in an enhancement of electrical conductiv- ity. ${ }^{7,37}$ In conclusion, a significant increase in dc conductivity with addition up to $10 \mathrm{~mol} \% \mathrm{GeO}_{2}$ is attributed to the presence of various phosphate units and tetrahedral germanium units that contain nonbridging oxygens. However, it seems that in these glass structures the homoatomic $\mathrm{P}-\mathrm{O}-\mathrm{P}$ and $\mathrm{Ge}-\mathrm{O}-$ Ge linkages are dominated resulting in an easy migration of $\mathrm{Li}^{+}$ ions along these bonds. This is consistent with spectroscopic findings for ternary germanophosphate glasses. ${ }^{33}$

With further addition of $\mathrm{GeO}_{2}$ from 15 to $25 \mathrm{~mol} \%$, the dc conductivity increases slightly. Closer inspection of Raman spectra shows further incorporation of germanium units into the phosphate network. Thus, along with significant changes in phosphate structure, the formation of $\mathrm{GeO}_{4}$ and $\mathrm{GeO}_{6}$ units is observed. It seems that the formation of higher-coordinated germanium units is responsible for higher connectivity in these glasses, which leads to the formation of heteroatomic $\mathrm{P}-\mathrm{O}-\mathrm{Ge}$ bonds. The presence of a large amount of germanate units increases the anionic character of germanium species, which can be stabilized by the interaction with pyrophosphate units. Such an interaction probably contributes to the preferential heteroatomic $\mathrm{P}-\mathrm{O}-\mathrm{Ge}$ linkage over homoatomic $\mathrm{P}-\mathrm{O}-\mathrm{P}$ and $\mathrm{Ge}-\mathrm{O}-\mathrm{Ge}$ bonds. ${ }^{33}$ Therefore, the formation of $\mathrm{P}-\mathrm{O}-\mathrm{Ge}$ bonds is responsible for slight decrease in the $\mathrm{Li}^{+}$ions mobility because $\mathrm{Li}^{+}$ions are involved in charge stabilization of these bonds and in turn tend to reach maximum. It seems that the conversion of $\mathrm{GeO}_{4}$ to $\mathrm{GeO}_{6}$ and incorporation of germanium units into phosphate chains decrease the average bond distance of $\mathrm{Li}^{+}$ions. Moreover, the incorporation of germanate units leads to the increase of the network reticulation by the formation of $\mathrm{P}-\mathrm{O}-\mathrm{Ge}$ bonds and thereby to an enhanced degree of the compaction in glass structure.

Although the $\mathrm{B}_{2} \mathrm{O}_{3}$ content was kept fixed at $10 \mathrm{~mol} \%$, the addition of $\mathrm{GeO}_{2}$ influences the boron structure by converting $\mathrm{BO}_{4}$ to $\mathrm{BO}_{3}$ units (Figure 3). As was previously reported, there is a relationship between $\mathrm{BO}_{3} / \mathrm{BO}_{4}$ ratio and electrical conductivity. ${ }^{5,11}$ At lower $\mathrm{GeO}_{2}$ content, the dominant borate units are $\mathrm{BO}_{4}$ whose charge is more delocalized in comparison to the phosphate units. Therefore, these anionic $\mathrm{BO}_{4}$ units enhance the ion transport. In contrast, the formation of neutral $\mathrm{BO}_{3}$ units, $7 \%$, of the total number of boron units at higher $\mathrm{GeO}_{2}$ content could break the conduction pathways and reduce the $\mathrm{Li}^{+}$ions mobility. ${ }^{11,15}$

Regarding the behavior of the ionic conductivity in disordered solids such as glasses, the ion motion could be described as activated hopping between different ion sites. The ions vibrate most of the time in the potential-energy minimum, which is ordered by the distribution of depths and barrier heights in surrounding matrix. The variation in energy is a result of various binding energies at ion sites and interactions between the ions. ${ }^{27}$ Generally, the long-range transport leads to the low-frequency plateau characterized by the dc conductivity, whereas at higher frequency, the dispersive conductivity is related to the back-and-forth motion over limited ranges. In glasses containing a high concentration of mobile ions, on short-time scales only a small part of the ions is involved in back-and-forth motion. ${ }^{27,28}$

As mentioned earlier, the conductivity dispersion is analyzed by Jonscher's law where the power law exponent $s$ is related to the interactions between ions. Because exponent $s$ depends on both the frequency and temperature, the decrease in $s$ with increasing the temperature is consistent with the correlated back-and-forth hopping where the ion transport is due to hopping between potential barriers (Figure 10). With 
increasing temperature, the interaction between ions increases, which leads to the decrease in s. For this series of glasses the exponent $s$ reaches the value $s=0.65 \pm 0.04$ at about $270 \mathrm{~K}$, which is in good agreement with typical value for oxide glasses, $s=0.67 \pm 0.03 .{ }^{29}$ In contrast, with the addition of $\mathrm{GeO}_{2}$, the $s$ exponent is almost constant because of the formation of more unstable sites in glass network.

It is well-known that the imaginary part of ac conductivity is related to the real part of the frequency-dependent dielectric permittivity. It is generally known that at the high frequencies the dielectric permittivity represents the ion motion in the glass bulk whereas at the low-frequency region it is associated with the electrode polarization as shown in Figure 11a. Of course, one has to consider the effect of temperature as well. For the glasses in the present study the increase in $\varepsilon^{\prime}(\omega)$ with increasing $\mathrm{GeO}_{2}$ content is attributed to the increase in the electrical conductivity (Table 3 ).

It was reported earlier that $\Delta \varepsilon^{\prime}$ is a quantity that depends on $\mathrm{Li}^{+}$ions hopping, and its variations are associated with the changes in hopping dynamics. ${ }^{30}$ The values of $\Delta \varepsilon^{\prime}$ exhibited in Figure 12 clearly show a progressive increase with increasing $\mathrm{GeO}_{2}$ content up to $15 \mathrm{~mol} \%$. Such an increase suggests that the $\Delta \varepsilon^{\prime}$ is related to the modification in glass network. On close inspection of the obtained results, the significant increase in conductivity lies at about $10 \mathrm{~mol} \%$ of $\mathrm{GeO}_{2}$ where the germanium units in tetrahedral coordination are interconnected to depolymerized phosphorus units. Therefore, slightly delocalized negative charge of $\left[\mathrm{GeO}_{4}\right]^{-}$units is compensated for by $\mathrm{Li}^{+}$ions, which are less tightly bound leading to an increase in electrical conductivity. In contrast, at $15 \mathrm{~mol} \%$ $\mathrm{GeO}_{2}$, more pronounced conversion of $\mathrm{GeO}_{4}$ to $\mathrm{GeO}_{6}$ units along with the incorporation of germanium units into phosphate network is observed (Figure 4). This probably causes an increase in binding energy, which reduces $\mathrm{Li}^{+}$ions mobility, so the maximum in $\Delta \varepsilon^{\prime}$ at $15 \mathrm{~mol} \%$ of $\mathrm{GeO}_{2}$ reflects the changes in the glass network. This study clearly shows that the $\Delta \varepsilon^{\prime}$ depends not only on the hopping dynamics, i.e., concentration of mobile ions, but also on the modification of glass structure that contains structural units with lower charge density that support an easy migration of $\mathrm{Li}^{+}$ions.

The information regarding the relaxation phenomena is provided by conductivity relaxation model investigating the complex impedance, $Z^{*}(\omega)$, and complex dielectric modulus, $M^{*}(\omega)$, as a function of frequency and temperature. The absence of the $\varepsilon^{\prime \prime}(\omega)$ loss peak associated with the long-range ions diffusion positioned at low-frequency region often is hidden by electrode polarization. However, for the present glasses, the long-range relaxation is represented by well-defined peak in $Z^{\prime \prime}(\omega)$ appearing at lower frequency (Figure 13). The maximum of $Z^{\prime \prime}(\omega)$ is determined by the ionic conductivity in bulk and exhibited at higher frequency. However, at lower frequency additional contribution to the impedance from the sample/electrode interfaces appeared especially at higher temperatures, $273 \mathrm{~K}$, as can be seen in Figure 13. The spacecharge layers formed near metal electrodes are responsible for the bulk polarization and sharp decrease of the conductivity.

In the dielectric modulus representation, the effect of electrode polarization is avoided because $M^{\prime \prime}(\omega)$ peaks are shifted to the higher frequency with respect to $Z^{\prime \prime}(\omega)$. The relaxation times, $\tau_{Z^{\prime \prime}}$ and $\tau_{M^{\prime \prime}}$, calculated from the frequency at $Z^{\prime \prime}(\omega)$ and $M^{\prime \prime}(\omega)$ maxima, shown in Figure 13, and listed in Table 3, are thermally activated with the following respective activation energies $E_{Z^{\prime \prime}}$ and $E_{M^{\prime \prime}}$. It is clear from Table 3 that both relaxation times, $\tau_{Z^{\prime \prime}}$ and $\tau_{M^{\prime \prime}}$, rapidly decrease up to 10 mol $\% \mathrm{GeO}_{2}$ because of significant decreases in activation energies, $E_{\mathrm{dc}} E_{Z^{\prime \prime}}$, and $E_{M^{\prime \prime}}$. For glasses containing up to $25 \mathrm{~mol}$ $\% \mathrm{GeO}_{2}$, the relaxation times continue to decrease slightly, which causes a reduced increase in electrical conductivity.

It was previously mentioned that by combining imaginary modulus with imaginary impedance it is possible to characterize the relaxation effects and ionic hopping conductivity processes within bulk of glasses. For this series of glasses, a very close maximum position of $Z^{\prime \prime} / Z^{\prime \prime}{ }_{\text {max }}$ and $M^{\prime \prime} / M^{\prime \prime}{ }_{\text {max }}$ peaks represented for Ge-15 glass in Figure 13 indicates the presence of both the relaxation polarization process and conduction. Clearly, the observed overlapping of $Z^{\prime \prime} / Z^{\prime \prime}{ }_{\text {max }}$ and $M^{\prime \prime} / M^{\prime \prime}{ }_{\text {max }}$ peaks illustrates that the dynamics process occurring at different frequencies shows the same thermal activation energy and existence of a single charge carriers. Therefore, both $Z^{\prime \prime} / Z^{\prime \prime}{ }_{\max }$ and $M^{\prime \prime} / M^{\prime \prime}{ }_{\text {max }}$ peaks describe the same relaxation process.

\section{CONCLUSIONS}

The gradual introduction of the third glass former, $\mathrm{GeO}_{2}$, to the borophosphate network with constant $\mathrm{Li}^{+}$concentration causes the structural modifications responsible for the continuous increase in electrical conductivity. The structural investigation of $40 \mathrm{Li}_{2} \mathrm{O}-10 \mathrm{~B}_{2} \mathrm{O}_{3}-(50-x) \mathrm{P}_{2} \mathrm{O}_{5}-x \mathrm{GeO}_{2}, x=0-25 \mathrm{~mol} \%$, glasses shows the systematic depolymerization of phosphate chains with the addition of germanium oxide. The rapid increase in the dc conductivity for glasses containing up to 10 mol $\% \mathrm{GeO}_{2}$ is attributed to the interconnection between slightly negatively charged $\left[\mathrm{GeO}_{4}\right]^{-}$units and depolymerized phosphate anions, which facilitate mobility of $\mathrm{Li}^{+}$ions. In this compositional region, depolymerization plays an important role on the nonrandom hopping of $\mathrm{Li}^{+}$ions because the $\mathrm{Li}^{+}$ions are shared between two glass-former units with dispersed charges, which leads to the less effectively bonded $\mathrm{Li}^{+}$ions. In particular, we could clearly discern the role played by increased amount of $\mathrm{GeO}_{4}$ tetrahedra and further conversion to the $\mathrm{GeO}_{6}$ units as $\mathrm{GeO}_{2}$ content increased. This enhances the incorporation of germanium units into phosphate structure, increasing the degree of compaction of the glass structure, which improves the $\mathrm{Li}^{+}$ions mobility. The stronger cross-linkage in glass network through the formation of higher amount of $\mathrm{P}-\mathrm{O}-\mathrm{Ge}$ bonds creates a stronger interaction of $\mathrm{Li}^{+}$ions and germanophosphate network, which in turns tends to reach a maximum in the $\mathrm{Li}^{+}$ions conductivity.

The dielectric properties such as $\varepsilon^{\prime}(\omega)$ and $\varepsilon^{\prime \prime}(\omega)$ and their variation with temperature and frequency indicate a dispersion at lower frequency related to the relaxation polarization process. The relaxation observed on the $Z^{\prime \prime}(\omega)$ and $M^{\prime \prime}(\omega)$ spectra is correlated to both long-range hopping and electrical relaxation. The overlapping of $Z^{\prime \prime} / Z^{\prime \prime}{ }_{\max }$ and $M^{\prime \prime} / M^{\prime \prime}{ }_{\max }$ peaks suggests the same activation energy and existence of the single carrier, both of which are related to the same relaxation processes.

\section{AUTHOR INFORMATION}

\section{Corresponding Author}

*Tel.:+385-1-4561-149. E-mail: mogus@irb.hr.

\section{Notes}

The authors declare no competing financial interest. 


\section{ACKNOWLEDGMENTS}

This work was supported by the Croatian Science Foundation; project IP-09-2014-5863. Czech authors are also grateful for the financial support from the Grant Agency of the Czech Republic (Grant No. 13-00355S). We thank Prof. L. Montagne and Dr. B. Revel for the MAS NMR measurements. A.M.M. and K.S. would like to thank Dr. R. D. Banhatti for critically reading this manuscript.

\section{REFERENCES}

(1) Duclot, M.; Souquet, J.-L. Glassy Materials for Lithium Batteries: Electrochemical Properties and Devices Performances. J. Power Sources 2001, 97-98, 610-615.

(2) Ritchie, A. G. Recent Developments and Likely Advances in Lithium Rechargeable Batteries. J. Power Sources 2004, 136, 285-289.

(3) Dudney, N. J. Glass and ceramic electrolytes for lithium and lithium-ion batteries. In Lithium batteries: Science and technology; Abbas Nazri, G., Pistoia, G., Eds.; Springer: New York, 2003.

(4) Cao, C.; Li, Z.; Wang, X.; Zhao, X.; Han, W. Recent Advances in Inorganic Solid Electrolytes for Lithium Batteries. Front. Energy Res. 2014, 2, 1-10.

(5) Zielniok, D.; Cramer, C.; Eckert, H. Structure/Properties Correlations in Ion-Conducting Mixed-Network Former Glasses: Solid-State NMR Studies of the System $\mathrm{Na}_{2} \mathrm{O}-\mathrm{B}_{2} \mathrm{O}_{3}-\mathrm{P}_{2} \mathrm{O}_{5}$. Chem. Mater. 2007, 19, 3162-3170.

(6) Agarwal, A.; Seth, V. P.; Gahlot, P. S.; Khasa, S.; Arora, M.; Gupta, S. K. Study of Electron Paramagnetic Resonance, Optical Transmission and Dc Conductivity of Vanadyl Doped $\mathrm{Bi}_{2} \mathrm{O}_{3} \cdot \mathrm{B}_{2} \mathrm{O}_{3}$. $\mathrm{Li}_{2} \mathrm{O}$ Glasses. J. Alloys Compd. 2004, 377, 225-231.

(7) Kumar, S.; Rao, K. J. Lithium Ion Transport in Germanophosphate Glasses. Solid State Ionics 2004, 170, 191-199.

(8) Prasad, P. S. S.; Rani, A. N. D.; Radhakrishna, S. Mixed Glass Former Effect in AgI- $\mathrm{Ag}_{2} \mathrm{O}-\mathrm{V}_{2} \mathrm{O}_{5}-\mathrm{P}_{2} \mathrm{O}_{5}$ Quaternary Amorphous Solid Electrolytes. Mater. Chem. Phys. 1990, 25, 487-499.

(9) Magistris, A.; Chiodelli, G.; Villa, M. Lithium Borophosphate Vitreous Electrolytes. J. Power Sources 1985, 14, 87-91.

(10) Muñoz, F.; Montagne, L.; Pascual, L.; Durán, A. Composition and Structure Dependence of the Properties of Lithium Borophosphate Glasses Showing Boron Anomaly. J. Non-Cryst. Solids 2009, 355, 2571-2577.

(11) Raguenet, B.; Tricot, G.; Silly, G.; Ribes, M.; Pradel, A. The Mixed Glass Former Effect in Twin-Roller Quenched Lithium Borophosphate Glasses. Solid State Ionics 2012, 208, 25-30.

(12) Tho, T. D.; Prasada Rao, R.; Adams, S. Structure Property Correlation in Lithium Borophosphate Glasses. Eur. Phys. J. E: Soft Matter Biol. Phys. 2012, 35 (8), 1-11.

(13) Larink, D.; Eckert, H.; Reichert, M.; Martin, S. W. Mixed Network Former Effect in Ion-Conducting Alkali Borophosphate Glasses: Structure/Property Correlations in the System $\left[\mathrm{M}_{2} \mathrm{O}\right]_{1 / 3}\left[\left(\mathrm{~B}_{2} \mathrm{O}_{3}\right)_{\mathrm{x}}\left(\mathrm{P}_{2} \mathrm{O}_{5}\right)_{1-x}\right]_{2 / 3}(\mathrm{M}=\mathrm{Li}, \mathrm{K}, \mathrm{Cs})$. J. Phys. Chem. C 2012, 116, 26162-26176.

(14) Ren, J.; Eckert, H. Quantification of Short and Medium Range Order in Mixed Network Former Glasses of the System $\mathrm{GeO}_{2}-$ $\mathrm{NaPO}_{3}$ : A Combined NMR and X-ray Photoelectron Spectroscopy Study. J. Phys. Chem. C 2012, 116, 12747-12763.

(15) Moguš-Milanković, A.; Sklepić, K.; Blažanović, H.; Mošner, P.; Vorokhta, M.; Koudelka, L. Influence of Germanium Oxide Addition on the Electrical Properties of $\mathrm{Li}_{2} \mathrm{O}-\mathrm{B}_{2} \mathrm{O}_{3}-\mathrm{P}_{2} \mathrm{O}_{5}$ Glasses. J. Power Sources 2013, 242, 91-98.

(16) Mošner, P.; Vorokhta, M.; Koudelka, L.; Montagne, L.; Revel, B.; Sklepić, K.; Moguš Milanković, A. Effect of Germanium Oxide on the Structure and Properties of Lithium Borophosphate Glasses. J. Non-Cryst. Solids 2013, 375, 1-6.

(17) Lide, D. R. CRC Handbook of Chemistry and Physics; CRC Press: Boca Raton, FL, 2001.

(18) Brow, R. K. Review: the Structure of Simple Phosphate Glasses. J. Non-Cryst. Solids 2000, 263-264, 1-28.
(19) Kumar, S.; Murugavel, S.; Rao, K. J. Absence of Germanate Anomaly in Ternary Lithium Germanophosphate Glasses: Modification Behavior of Mixed Glass System of Strong and Fragile Formers. J. Phys. Chem. B 2001, 105, 5862-5873.

(20) Ray, N. H. Inorganic Polymers; Academic Press: London, 1978.

(21) Henderson, G. S. The Germanate Anomaly: What Do We Know? J. Non-Cryst. Solids 2007, 353, 1695-2004.

(22) Evstropiev, K. S.; Ivanov, A. O. In Advances in Glass Technology, Part 2; Matson, F. R., Rindone, G. E., Eds.; Plenum: New York, 1963.

(23) Nelson, B. N.; Exarhos, G. J. Vibrational Spectroscopy of Cation-Site Interactions in Phopshate Glasses. J. Chem. Phys. 1979, 71, 2739-2747.

(24) Jonscher, A. K. Dielectric Relaxation in Solids; Chelsea Dielectric Press: London, 1996

(25) Almond, D. P.; Duncan, G. K.; West, A. R. The Determination of Hopping Rates and Carrier Concentrations in Ionic Conductors by a New Analysis of Ac Conductivity. Solid State Ionics 1983, 8, 159164.

(26) Almond, D. P.; West, A. R. Mobile Ion Concentrations in Solid Electrolytes from an Analysis of AC Conductivity. Solid State Ionics 1983, 9-10, 277-282.

(27) Dyre, J. C.; Maass, P.; Roling, B.; Sidebottom, D. L. Fundamental Questions Related to Ion Conducting in Disordered Solids. Rep. Prog. Phys. 2009, 72, 046501.

(28) Funke, K.; Roling, R.; Lange, M. Dynamics of mobile ions in crystals, glasses and melts. Solid State Ionics 1998, 105, 195-208.

(29) Sidebottom, D. L. Evidence for Site Memory Effects in the Ionic Relaxation of $\left(\mathrm{Li}_{2} \mathrm{O}\right)_{\mathrm{x}}\left(\mathrm{Na}_{2} \mathrm{O}\right)_{\mathrm{y}}\left(\mathrm{GeO}_{2}\right)_{1-x-\mathrm{y}^{*}}$ J. Non-Cryst. Solids 1999, 255, 67-77.

(30) Sidebottom, D. L.; Zhang, J. Scaling of the Ac Permittivity in Ion-Conducting Glasses. Phys. Rev. B: Condens. Matter Mater. Phys. 2000, 62, 5503-5507.

(31) Sidebottom, D. L. Influence of Cation Constriction on the Ac Condcutivity Dispersion in Metaphosphate Glasses. Phys. Rev. B: Condens. Matter Mater. Phys. 2000, 61, 14507-14516.

(32) Šantić, A.; Kim, C. W.; Day, D. E.; Moguš-Milanković, A. Electrical Properties of $\mathrm{Cr}_{2} \mathrm{O}_{3}-\mathrm{Fe}_{2} \mathrm{O}_{3}-\mathrm{P}_{2} \mathrm{O}_{5}$ Glasses. Part II. J. NonCryst. Solids 2010, 356, 2699-2703.

(33) Behrends, F.; Eckert, H. Mixed Network Former Effects in Oxide Glasses: Spectroscopic Studies in the System $\left(\mathrm{M}_{2} \mathrm{O}\right)_{1 / 3}\left[\left(\mathrm{Ge}_{2} \mathrm{O}_{4}\right)_{\mathrm{x}}\left(\mathrm{P}_{2} \mathrm{O}_{5}\right)_{1-x}\right]_{2 / 3}$. J. Phys. Chem. C 2014, 118, $10271-10283$.

(34) Sahar, M. R.; Wahab, A.; Hussein, M. A.; Hussin, R. Structural Cheracterization of $\mathrm{Na}_{2} \mathrm{O}-\mathrm{P}_{2} \mathrm{O}_{5}-\mathrm{GeO}_{2}$ Glass System. J. Non-Cryst. Solids 2007, 353, 1134-1140.

(35) Henderson, G. S.; Amos, R. T. The Structure of Alkali Germanophosphate Glasses by Raman Spectroscopy. J. Non-Cryst. Solids 2003, 328, 1-19.

(36) Storek, M.; Böhmer, R.; Martin, S. W.; Larink, D.; Eckert, H. NMR and Conductivity Studies of the Mixed Glass Former Effect in Lithium Borophosphate Glasses. J. Chem. Phys. 2012, 137, 124507.

(37) Moguš-Milanković, A.; Šantić, A.; Reis, S. T.; Furić, K.; Day, D. E. Mixed Ion-Polaron Transport in $\mathrm{Na}_{2} \mathrm{O}-\mathrm{PbO}-\mathrm{Fe}_{2} \mathrm{O}_{3}-\mathrm{P}_{2} \mathrm{O}_{5}$ Glasses. J. Non-Cryst. Solids 2004, 342, 97-109. 